\title{
QUEM FAZ RIR? - DAS MÁSCARAS CÔMICAS DOS SUJEITOS DO RISO
}

\author{
WHO DOES LAUGH? - THE COMICAL MASKS OF THE SUBJECTS OF LAUGHTER
}

\author{
Rony Petterson Gomes do Vale \\ Universidade Federal de Minas Gerais
}

\begin{abstract}
RESUMO: Quando se trata de uma análise do discurso humorístico que alia questões sociais e linguageiras, acreditamos que haja uma preocupação em se fazer referência aos variados tipos de sujeitos que desejam ou precisam utilizar, de alguma maneira, a linguagem do riso, como, por exemplo, o bufão ou o bobo. Uma pergunta, entretanto, deve ser feita: o que se entende por essas identidades? Neste trabalho, discutimos uma questão que consideramos central para a análise do discurso humorístico relacionada às identidades (psicossociais e discursivas) e aos lugares dos sujeitos do riso, a saber: quais são as identidades prototípicas aferidas a esses sujeitos? Propomos uma descrição sucinta dos perfis, isto é, das "máscaras cômicas" dos sujeitos que ao longo da história se dedicaram à arte do fazer rir. Juntamente com uma caracterização histórica que indique as propriedades da legitimação aferida a esses sujeitos, essa apresentação se volta mais atentamente para as marcas que caracterizaram/caracterizam o discurso dos profissionais do riso, de modo que nos possibilite ter uma panorâmica das representações sociodiscursivas presentes nos diferentes ethé dos sujeitos do riso em geral.
\end{abstract}

PALAVRAS-CHAVE: ethos; identidades psicossociais e discursivas; sujeitos do riso; discurso humorístico.

ABSTRACT: When it comes to an analysis of "discourse humoristic" that combines social and language studies, we believe that there is a concern in reference to various types of subjects ("actors") who wish or need to use, in some way, the language of laughter, for example, the jester or fool. One question, however, must be asked: what is meant by these identities? In this paper, we discuss a matter that we consider central to the analysis of the discourse humoristic related to the identities (psychosocial and discursive) and places the subject of laughter: what are the prototypical identities checked these subjects? We propose a summary of the profiles, this is, the "comic masks" of the individuals who throughout history have dedicated themselves to the art of making people laugh. Along with a historical characterization indicate that the properties of the measured legitimacy to these subjects, this presentation turns more closely at the marks that characterize the discourse of "professionals of the laugh", so that enables us to have an overview of the socio-discursive representations present the different ethé the subject of laughter in general.

KEYWORDS: ethos; psychosocial and discursive identities; subject of laughter; discourse humoristic. 


\section{Revista do SELL}

v. $4, n^{\circ} .2$

ISSN: $1983-3873$

INTRODUÇÃO

A princípio, identificar identidades psicossociais, mesmo que prototípicas, dos sujeitos do riso se nos apresentava como uma empresa fadada ao malogro; todavia, da mesma maneira que a tradição nos legou uma gama de conhecimentos sobre as causas (linguísticas e não linguísticas), os efeitos (visados e concretos), as questões éticas, entre outras ligadas ao riso e ao fazer rir, esses mesmos estudos - para não dizer a vida também têm muito a nos ensinar a respeitos desses seres (personagens, figuras, atores) que representam a arte, no sentido não só de dom, mas também de técnica, do fazer rir.

Nesse passo, podemos assumir que tais seres, vez por outra, são conjurados em enunciados do tipo: "não se faça de bobo!"; "não faça papel de palhaço"; "você está espirituoso hoje!" etc. Esses enunciados, a nosso ver, refletem não só a existência dessas identidades nos imaginários sociodiscursivos, mas também que essas identidades, muitas vezes, se apresentam como máscaras que qualquer sujeito pode adotar (consciente ou inconscientemente) quando se aventura a fazer um chiste, contar uma piada, escrever um texto jocoso, apresentar um stand up, ou seja, uma "máscara cômica" adaptável (pelo/no discurso) a qualquer sujeito que vise fazer rir.

Nesse sentido, Bakhtin, tratando especificamente do trapaceiro, do bufão e do bobo, reflete a possibilidade de essas figuras, ao deixarem a vida e os palcos e adentrarem o universo do romance, se consubstanciarem em máscaras para o autor. De modo geral, Bakhtin (2010b, p. 195 et seq.) nos diz que, enquanto o trapaceiro busca a legitimação do seu dizer no embuste alegre permitido e aceito entre os mentirosos, e o bobo a possui devido à simploriedade (patética) justificada pela sua incapacidade de compreensão; o bufão, como um amálgama dos dois sujeitos anteriores, constrói a legitimação do seu discurso por meio de uma incompreensão fingida e por uma distorção das verdades socialmente admitidas, apoiando-se no caráter diferenciado de sua posição social. Assim, é possível ao bufão desenvolver um discurso que fala com uma "linguagem não reconhecível" e que deturpa "maldosamente as linguagens reconhecidas".

Partindo dessa ideia, Bakhtin (2010b, p. 275-276) ressalta que a introdução desses sujeitos no universo ficcional trouxe para a literatura: i) uma ligação estreita com os palcos teatrais e os espetáculos de máscaras ao ar livre; ii) um sentido figurado especial para o discurso desses sujeitos enquanto personagens: "tudo o que fazem e dizem não têm sentido direto e imediato, mas figurado e, às vezes, invertido"; iii) a criação de uma situação (paradoxal) de exclusão/inclusão: eles "não são deste mundo", não se 


\section{Revista do SELL}

v. $4, n^{\circ} .2$

ISSN: $1983-3873$

solidarizam com ele, e o veem pelo avesso; iv) uma forte influência sobre o estatuto de autor no romance, "sobre a sua imagem, se ela aparecia de um modo ou de outro" e "sobre seu ponto de vista".

Com respeito a esse último ponto, Bakhtin (2010b, p. 277-278) nos esclarece que, desse modo, as máscaras de bufão e de bobo vêm em socorro do romancista e que, além disso, elas "não são inventadas, elas têm suas raízes populares muito profundas". Com tais máscaras, o romancista é capaz de refletir e revelar, publicamente, esferas da vida especialmente privada (por exemplo, a esfera da sexualidade) e, ao mesmo tempo, promover "a denúncia de toda espécie de convencionalismo pernicioso, falso, nas relações humanas".

Como podemos perceber, Bakhtin nos explica esses pontos tendo por fundo a construção do romance, mas podemos nos perguntar: se isto é possível no romance, por que não o seria em outros gêneros? Quanto a isso, as palavras do próprio Bakhtin são esclarecedoras:

\footnotetext{
$\mathrm{Na}$ luta contra o convencionalismo e a inadequação de todas as formas de vida existentes, por um homem verdadeiro, essas máscaras adquirem um significado excepcional. Elas dão o direito de não compreender, de confundir, de arremedar, de hiperbolizar a vida; o direito de falar parodiando, de não ser literal, de não ser o próprio indivíduo... (BAKHTIN, 2010b, p. 278)
}

Portanto, as máscaras se apresentam, no nosso entender, como um princípio organizador do(s) discurso(s) em geral não somente de um indivíduo que não participa desse convencionalismo e não o compreende, mas também de um sujeito que não deseja dele participar; ou, pelo contrário, que o compreende (às vezes, até muito bem) e deseja denunciar as suas incoerências. Com efeito, ao darmos atenção para essa questão das máscaras, podemos dizer que esse sujeito, com a finalidade de elaborar diferentes formas de riso e, por conseguinte, diferentes gêneros do discurso, pode ajustar seu ethos, baseando-se ora num afastamento, ora numa aproximação das representações sóciohistóricas dos bufões, bobos, satíricos...

De fato, numa perspectiva linguageira, Charaudeau (2006, p. 64) nos assegura que "o ser de palavra, quer queira quer não, é sempre um duplo. Uma parte dele mesmo se refugia em sua legitimidade de ser social, outra se quer construída pelo que diz seu discurso". Em outras palavras, a identidade discursiva e a identidade psicossocial interagem, mesclam-se, garantindo a legitimidade do sujeito do discurso. E embora estejam fortemente imbricadas durante $o$ ato de linguagem, essas identidades podem, por 


\section{Revista do SELL \\ v. $4, n^{\circ} .2$ \\ ISSN: $1983-3873$}

uma abstração metodológica, ser separadas para que melhor se entenda (e se explique) os efeitos de sentido possíveis resultantes dessa mescla.

Nessa linha de raciocínio, Charaudeau (2011, p. 17) nos adverte que, para a análise do humor, o problema que se coloca é saber se o sujeito tem autorização, dentro de uma dada situação, para realizar seu ACH. Essa autorização, ou melhor dizendo, essa legitimação se relaciona, às vezes, a um só tempo: i) à natureza do interlocutor; ii) ao tipo de relação instalada entre os interlocutores; iii) às circunstâncias materiais; iv) ao lugar ocupado pelo sujeito falante na situação de comunicação; e v) à construção do ethos. No decorrer de seu texto, entretanto, Charaudeau (2011) concede maior ênfase aos elementos da situação de comunicação em detrimento da identidade psicossocial. Isso porque, para ele, o humor deve ser entendido antes como uma estratégia discursiva do que um tipo de discurso propriamente dito. Se se adota essa postura, os sujeitos do riso que representaram/representam o fazer rir perdem a possibilidade de serem tomados enquanto modelos/protótipos para a construção dos ethé discursivos, ou para a reformulação dos ethé prévios durante o uso da LR.

Em vista disso, nosso intuito é mostrar que a legitimidade do sujeito-humorista também pode ser buscada por meio das identidades psicossociais não somente no sentido restrito no qual Charaudeau (2006) as define, mas também em um sentido amplo, vale dizer, relacionando-as às representações sociais armazenadas nos imaginários sociodiscursivos sobre os profissionais do riso. Isso nos leva, portanto, a situar a legitimidade desses sujeitos em particular em relação:

- À posição do sujeito numa dada hierarquia, aos momentos históricos e às profissões ligadas ao riso, marcando a tomada de palavra concedida pelo poder (do rei, por exemplo), pelo acontecimento (feira, festa, carnaval), ou pelo mídium (circo, teatro, jornal, rádio, TV, internet);

- À imagem do fiador (enquanto bufão, bobo, satírico...), isto é, em relação à representação do corpo do enunciador, reconstituída pelo ouvinte/leitor, (MAINGUENEAU, 2004) a qual garante o dizer, dando suporte, por exemplo, a escolha de determinados expedientes linguísticos e discursivos como, por exemplo, o uso da excrementícia, da lubricidade, da chularia, ou mesmo da verdade, muitas vezes interditos devido às coerções do contrato e/ou da situação de comunicação; 


\section{Revista do SELL}

v. $4, n^{\circ} .2$

ISSN: $1983-3873$

- À autoridade adquirida pelo discurso. Nesse caso, trata-se do argumento de autoridade pelo avesso. Aqui, tocamos no ponto crítico entre o que se considera um discurso sério e um discurso não sério: por exemplo, o discurso do bobo da corte diz sem dizer ao mesmo tempo em que diz o que é preciso dizer; no entanto, os demais membros da corte podem, quase sempre, encontrar uma terceira via para o rei: "não leve essas palavras (besteiras ou verdades) a sério, ele é só um bobo!".

Destarte, apresentamos, nas páginas seguintes, uma descrição sucinta dos perfis dos sujeitos que ao longo da história se dedicaram à arte do fazer rir. Todavia, diante da impossibilidade de construir uma trajetória histórica que aborde todos esses sujeitos, selecionamos os profissionais que, no nosso entender, exerceram um papel fundamental nos discursos ligados ao riso, além, é claro, da sua representatividade no imaginário ocidental.

\subsection{A QUESTÃO DAS DENOMINAÇÕES DOS PROFISSIONAIS DO RISO}

Ao longo da história, aos profissionais do riso foram atribuídos diferentes termos de acordo com as sociedades e as culturas. Com isso, a grande maioria dos termos que encontramos em língua portuguesa, como, por exemplo, bufão, cômico ou palhaço, têm sua origem em outras línguas e, além disso, estão, por vezes, marcados historicamente. Como consequência direta disso, podemos ler, nas traduções de Aristóteles, Cícero ou Quintiliano, verba gratia, o termo escurra - que, como sabemos, não necessariamente desempenhava a profissão de fazer rir - vertido para o português como bufão, bobo ou palhaço.

Não queremos aqui entrar nas querelas sobre os problemas de tradução de termos interlínguas, uma vez que os limites (sutis) de sentido entre os termos relacionados ao riso e ao risível fazem com que os termos ligados a esses sujeitos se tornem, de certo modo, tênues. Destacaremos somente que, devido a esses problemas, optamos por organizar nossa apresentação como um percurso que leve em consideração os termos marcados historicamente, fazendo referência, sempre que possível, ao termo na língua de origem. Isso, além de nos ajudar a diferenciar o status institucional que cada um desses sujeitos apresentou/apresenta, manterá nosso texto em coerência com os demais estudos sobre o riso e o risível. 


\section{Revista do SELL}

v. $4, n^{\circ} .2$

ISSN: $1983-3873$

Um exemplo: bobo é datado, em nossa língua, a partir do século XVI e possui sinonímia direta com termos como truão, bufo, bufão (HOUAISS, 2009). Este último, de

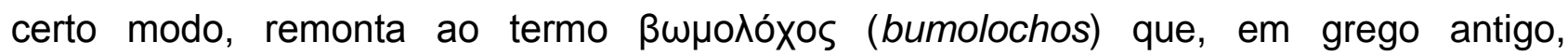
significava: 1) que se oculta junto de um altar para furtar ou mendigar as oferendas; mendigo, ladrão; 2) bufão; charlatão; 3) bufo; grosseiro; vulgar (MALHADAS; DEZOTTI; NEVES, 2006, p. 175). Nesse ponto, é importante evidenciar que é com esse termo que Aristóteles se refere, na Retórica, ao sujeito do riso do qual o homem urbano deveria se diferenciar ao utilizar o riso (cf. ARISTÓTELES, 2002, p. 186). Isso, por um lado, nos leva a propor que o termo bufão seja mais adequado do que bobo ou palhaço para tratar de um determinado sujeito que fazia rir na Antiguidade. Por outro, mesmo que o bufão não tenha desaparecido durante a Idade Média e o Renascimento, o termo bobo nos parece ser mais conveniente - aos nossos objetivos de propor modelos ethóticos - para designar, talvez, esse mesmo indivíduo (o bufão) cuja função de fazer rir, como mostraremos mais adiante, foi institucionalizada como profissão nas cortes medievais.

\subsection{AQUELE QUE FAZ RIR: ORIGENS E PERFIS}

\subsubsection{OS CÔMICOS: DE ADORADORES DE DIONÍSIO AOS SUJEITOS DA COMÉDIA}

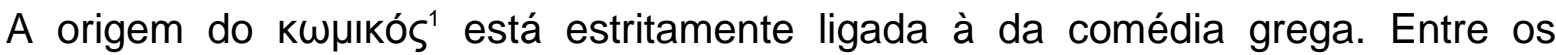
estudiosos da comédia clássica, costumam-se aceitar duas hipóteses de base etimológica, já presentes na Poética de Aristóteles. A primeira assume que os cômicos eram assim denominados, pelos antigos dórios, "porque, expulsos por desprezo da cidade, andavam à deriva pelos komai..." (ARISTÓTELES, 2004 p. 42). Disso, podemos inferir que, devido aos protestos e às manifestações agressivas e mordazes desses camponeses contra os cidadãos (LESKY, 1995, p. 265), a cidade relega esses indivíduos à $k \omega ́ \mu \eta^{2}$, talvez numa das primeiras reações sulfurosas contras os gelotopoioi ("aqueles que fazem rir").

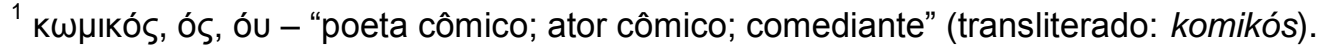

${ }^{2}$ kẃ $\mu \eta$, ns - "pequena aldeia"; "lugarejo"; "arredores da cidade", de acordo com a etimologia proposta de Aristóteles (transliterado: Komé).
} 


\section{Revista do SELL}

v. $4, n^{\circ} .2$

ISSN: $1983-3873$

A segunda hipótese relaciona os cômicos às festas religiosas em adoração a Dionísio, deus da alegria, da luxúria e do vinho, nas quais os $k \omega \mu o^{3}{ }^{3}$, numa alegria desenfreada, celebravam a renovação da vida por meio da embriaguez e do engodo numa espécie de carnaval (LESKY, 1995, p. 263-265). Mais aceita entre os estudiosos, essa hipótese se fundamenta no fato de que a esses interpretes dos cantos fálicos, adoradores de Dionísio, era permitido um discurso, alegre e, ao mesmo tempo, grosseiro que, posteriormente, deixaria a festa/culto para adentrar na arte poética: o uso de troças mordazes e pessoais entre os participantes e o público durante o cortejo passaria a constituir a parábase ${ }^{4}$ na comédia (JAEGER, 1995, p. 416). Tempos mais tarde, no entanto, esse mesmo discurso levaria a aristocracia grega a repudiar a comédia, atestando o perigo do riso. Com efeito, comediógrafos e atores cômicos, que se confundiam, eram tidos, muitas vezes, com desconfiança, devido à possibilidade de seus discursos sempre tenderem para o ridículo e para o escárnio. Para citar um exemplo, vejamos o caso de Aristófanes.

Reconhecido, à época, como promissor autor de comédias, durante os debates desenvolvidos no Banquete de Platão, Aristófanes é chamado, como os outros convidados, a fazer um elogio ao Amor (Eros). Entretanto, Erixímaco, ao perceber um tom faceto nas primeiras palavras de Aristófanes, indaga a este último da necessidade de manter seu discurso sob vigilância: "Meu caro Aristófanes, vê o que fazes. Estás a fazer graça, quando vais falar, e me forças a vigiar o teu discurso, se por ventura vais dizer algo risível, quando te é permitido falar em paz" (PLATÃO, 1985, p. 22). Aristófanes, porém, desenvolve seu elogio sobre o Amor de forma brilhante, sem a presença do risível tão temido por Erixímaco.

Esse contraste de atitudes, é importante notar, surge exatamente no mesmo diálogo em que Sócrates, ao fim do banquete, juntamente com outros convivas, procura defender um ponto de vista aparentemente contraditório às ideias defendidas por Platão em relação à arte da comédia:

[...] dos pormenores da conversa disse Aristodemos que não se lembrava - pois não assistira ao começo e ainda estava sonolento - em resumo porém, disse ele, forçava-os Sócrates a admitir que é de um mesmo homem o saber fazer uma

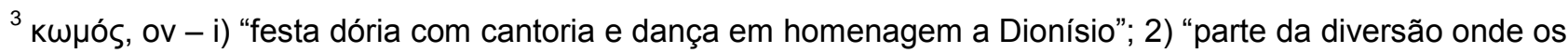
convidados percorrem as ruas, depois de uma festa ou um festival, com música, cantos e dança"; 3) "trupe impetuosa" (transliterado: kómos).

${ }^{4} \mathrm{Na}$ comédia clássica, "ocasião em que o coro se afastava da ação teatral e trazia o público de volta à realidade, abordando temas políticos e sociais" (HOUAISS, 2009).
} 


\section{Revista do SELL \\ v. $4, n^{\circ} .2$ \\ ISSN: $1983-3873$}

comédia e uma tragédia, e que aquele que com arte é poeta trágico é também um poeta cômico. (PLATÃO, 1985, p. 53)

Embora o texto de Platão deixe passar essa possibilidade de o poeta trágico usar seu engenho para a comédia, a questão que se coloca é que, nesse passo, a fala de Sócrates é retratada enquanto discurso reportado, o que não nos possibilita saber quais os argumentos foram utilizados para tentar persuadir os convivas. Aliás, esse apagamento do discurso direto de Sócrates faz jus a posição de Platão que não favorecia de modo algum o desenvolvimento de ideias em prol da comédia e do riso.

\subsubsection{O BUFÃO: DE ADULADOR NOS TEMPLOS A PSEUDOFILÓSOFO NOS BANQUETES}

Na seção anterior, vimos a preocupação de Erixímaco em relação ao risível em potência no discurso de Aristófanes. Para além dos comediógrafos e dos atores cômicos, essa preocupação durante os banquetes e as reuniões da sociedade grega se deve a outro gelotopoios que fez dessas situações o seu habitat natural.

Nas suas origens, o bufão tinha uma função religiosa. Na Grécia Antiga, o

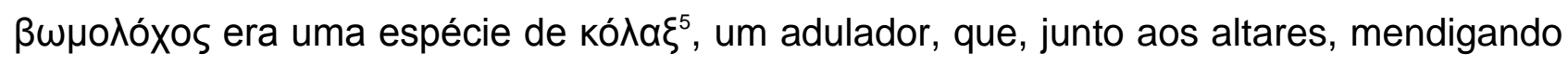
por comida, clamava pela piedade dos fieis durante os cultos. Mais tarde, essa adulação passa dos templos para os banquetes da boa sociedade; porém, não sem afetar também o comportamento do bumolochos "que deveria divertir os convidados com suas paródias, imitações, caretas burlescas. Às vezes, o bufão convidava-se a si próprio e, em troca de comida, devia fazer rir a companhia..." (MINOIS, 2003, p. 55). É importante evidenciar que essa mudança de topos também trouxe consigo, pelo menos nas primeiras épocas, uma legitimação para o bufão, considerado, agora, um ARETALoGvs ${ }^{6}$. Consequentemente, o discurso desse sujeito passa a ser reconhecido como uma pseudofilosofia: um discurso com tons moralizantes permeado de grosserias e absurdos (MINOIS, 2003, p. 56).

Desse modo, podemos dizer que essa "nova" condição de PARASITVs ${ }^{7}$ ressalta, ao mesmo tempo, as semelhanças e as diferenças entre os primeiros cômicos e os bufões, uma vez que estes últimos se especializaram em fazer rir em troca do "poder comer". No entanto, os bufões passaram a se organizar em grupos, a aprender técnicas como a

\footnotetext{
${ }^{5}$ кó $\alpha \xi$, akоऽ - "bajulador"; "adulador" (transliterado: kolaz).

${ }^{6}$ ARETALOGVS, I - "tagarela"; "charlatão".

7 PARASITVS, I - 1) "parasita”; "papa-jantares" (palavra da comédia), daí: 2) "hóspede, convidado”. Sentido figurado: 3) "comediante".
} 


\section{Revista do SELL}

v. $4, n^{\circ} .2$

ISSN: $1983-3873$

mímica, a dança (paródica), o malabarismo e a arte de dizer pilhérias (com os manuais de chalaça), e, além disso, eles ocupavam, agora, um espaço no anfiteatro, o que, no conjunto, provaria a institucionalização da profissão, segundo Minois (2003). Isso gerou 0 reconhecimento social de alguns grupos, como Os Sessenta de Atenas, que obtiveram fama a tal ponto de se tornarem referência sobre os assuntos gerais da polis: "os Sessenta disseram isso e aquilo", "acabo de chegar dos Sessenta" etc. (BREMMER, 2000, p. 33).

Apesar do sucesso desses bufões profissionais, a mesma preocupação da aristocracia grega, que, num primeiro momento, atingira os cômicos e os comediógrafos, recai agora sobre os bufões: "o bufão continua lá. Mas agora é de bom-tom desacreditálo" (MINOIS, 2003, p. 60). Da mesa do banquete, expurga-se a bufonaria. A adoção de normas de comportamento busca o controle do riso, tolerado, na aristocracia, somete em suas formas reduzidas (da ironia, da tirada ou do dito espirituoso). As reações das autoridades se voltam contra o bufão, agora relegado à barbearia (BREMMER, 2000, p. 34). Ou seja, o bufão passa de bajulador nos templos e nos banquetes para frequentador das soleiras da sociedade.

\subsubsection{O SATÍRICO: DE SEGUIDOR DE PÃ A CRÍTICO MORDAZ}

Embora RIDENDO CASTIGAT MORES seja a marca característica do discurso do satírico, isso, de modo algum, quer dizer que antes ${ }^{8}$ os demais gelotopoioi não fizeram crítica social - lembremos o destino dos bufões, a partir do momento em que seu discurso assume caráter mais crítico e agressivo. No entanto, parece que é na Roma Antiga ${ }^{9}$ que a crítica jocosa, com um caráter cáustico, altamente agressivo, direcionada aos vícios e, principalmente, às pessoas (em especial, aos poderosos), se desenvolveu de modo a se tornar modelo na poética e a ressoar como grito de protesto, somado ao riso, nas

\footnotetext{
8 "A Grécia, é verdade, conheceu a diatribe, forma agressiva e amarga de crítica social, desenvolvida pelos cínicos no quadro de discussões entre mestres e alunos. [...] Mas, enquanto a diatribe permaneceu ligada a uma escola filosófica, a sátira [em Roma] atinge uma dimensão nacional" (MINOIS, 2003, p. 87 - grifos nossos).

${ }^{9}$ Com base em Minois (2003, p. 84-85), podemos dizer que alguns fatores favoreceram o desenvolvimento da sátira em Roma, a saber: i) a causticidade camponesa nas origens do povo; ii) a língua latina que, com "suas formas elípticas, prestava-se maravilhosamente ao riso, na forma da dicacitas"; e iii) o caráter extremamente conservador da sociedade romana.
} 


\section{Revista do SELL}

v. $4, n^{\circ} .2$

ISSN: $1983-3873$

sociedades posteriores. Com os satíricos, vemos o riso adentrar ${ }^{10}$ na grande literatura, na classe dos escritores e dos poetas (Plauto, Juvenal, Catulo, Marcial, para citar alguns); porém, não sem a exigência do refinamento de comportamento baseado também nas prédicas de Aristóteles, Cícero, Horácio e, mais tarde, Quintiliano. Mas cabe agora perguntar: quem é o satírico, qual a sua origem e quais as características do seu discurso?

Etimologicamente, SATIRICVS ${ }^{11}$ remonta à SATVRA ${ }^{12}$, que, por sua vez, deriva de SATIRVS $^{13}$. A origem desses sujeitos designados pelo termo sátiro está relacionada também às festas dionisíacas e, de algum modo, às primeiras tragédias. Nessa linha, argumenta Lesky (1995, p. 255) que a hipótese da origem da tragédia como "canto dos bodes"

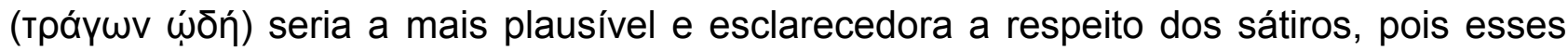
últimos (à moda de Pã: orelhas, rabo e patas de bode) teriam por pai Paposilenos que "traz sempre uma vestimenta à maneira de malha peluda [...] que nos seus filhos aparece como um rudimentar avental de pele peluda, em que está fixo o falo" (LESKY, 1995, p. 256). Isso os caracterizava os também como interpretes dos cantos fálicos; porém, diferentemente dos primeiros cômicos, os sátiros seriam portadores de um comportamento mais selvagem e de uma luxúria sem limites.

Ainda de acordo Lesky (1995), a presença dos sátiros nas primeiras manifestações dramáticas já havia sido apontada por Aristóteles, para quem, nos primeiros tempos, a tragédia seria composta de pequenos temas e de uma linguagem jocosa (o traço бatupıкóv $\left.{ }^{14}\right)$. Tempos mais tarde, a tragédia evoluiria para temas mais complexos, ficando o satyrikon reservado ao drama satírico. E é exatamente essa linguagem jocosa que vai

\footnotetext{
${ }^{10}$ É preciso lembrar que, em Roma, os demais profissionais do riso (o sannio (palhaço); o ethopoios (ator); o mimvs (mimo) entre outros) "pertenciam todos a uma classe diferente: eles são estrangeiros gregos, escravos ou servos" (GRAFF, 2000, p. 54). Exerciam sua atividade de fazer rir, mas não possuíam status de cidadão e, portanto, não tinha o poder de influenciar de modo decisivo na arte literária latina, devido à ausência de legitimação estabelecida a partir do ethos prévio, caro aos romanos.

${ }^{11}$ SATIRICVS, A, VM - "semelhante a um sátiro".

12 SATVRA, AE - 1) "mistura de prosa e verso, composição literária em que se misturam vários gêneros"; 2) "sátira dramática, espécie de farsa"; 3) "sátira literária, gêneros literário criado por Lucilius, em que se criticavam os vícios e as pessoas". As SATVRAE eram formadas de festivas e de dicacitas que, por sua vez, eram "divertimentos pastoris que consistiam em enviar de um grupo a outro, em réplicas alternadas, desaforos mordazes com uma métrica precisa". Com o tempo, essas SATVRAE evoluíram para uma "espécie de teatro total, misturando expressão corporal, canto, dança, palavra em uma atmosfera global" cuja função de derrisão era essencial (MINOIS, 2003, p. 85)

${ }^{13}$ SATIRVS, I - "sátiro" 1) "semideus companheiro de Baco, representado com orelhas, rabo e pés de cabra. Mais tarde, transforma-se em gênio rústico, confundido com fauno"; 2) "drama satírico em que tomavam parte os sátiros".

${ }^{14}$ батирıкóৎ, ń, óv - "semelhante a um sátiro"; "que concerne ao drama satírico".
} 


\section{Revista do SELL}

v. $4, n^{\circ} .2$

ISSN: $1983-3873$

se fixar na base das SATVRAE, originando, em Roma, a sátira enquanto gênero a partir do século II a. C.

Como apontamos anteriormente, a vida em Roma se apresentava propícia ao desenvolvimento da sátira: quase todos os poetas e escritores latinos se aventuram no gênero. Isso se deve, principalmente, ao fato de que a vida política nos últimos anos da República ainda não coibia o protesto com espada, e o riso era sabidamente uma arma contra os abusos e os maus costumes que se desenvolviam por influência dos estrangeiros e dos bárbaros, que abundavam a VRBES devido ao sucesso das campanhas militares romanas. Assim, o satírico se constitui "aparentemente" como arauto do povo contra os poderosos. Isso pois, os satíricos pertencem à classe aristocrática e, por isso mesmo, o seu discurso é uma espécie de defesa dos costumes dessa classe conservadora:

[...] fazer rir o povo das inovações das classes dirigentes para manter o vigor delas e aumentar a proteção da ordem; desencadear cinicamente um riso cujas verdadeiras vítimas são aqueles que riem. Zombar das taras dos aristocratas para guardar intacta a força da aristocracia... (MINOIS, 2003, p. 88)

Denunciando os vícios, os defeitos morais, as inovações (estrangeiras) nefastas, a insolência etc., o satírico, paradoxalmente, se torna mais conservador do que contestador, proporcionando a manutenção do status quo da aristocracia e dos seus costumes por meio do seu discurso.

\subsubsection{O BOBO: SUPERINTENDENTE DE BUFONARIA DE SUA MAJESTADE}

Havíamos anteriormente relatado que os termos bufão e bobo estão estreitamente imbricados e que a nossa preferência por bufão para designar um gelotopoios na Antiguidade se deve mais a motivos etimológicos do que propriamente semânticos outras designações como histrião, truão, escurra etc., por vezes, faziam também referência tanto ao bufão quanto ao bobo. Do mesmo modo, acreditamos que, para os objetivos desse trabalho, o termo bobo se apresenta mais adequado para circunscrever o sujeito do riso que adentrou o imaginário sociodiscursivo (através de fatos históricos e de criações ficcionais) devido à sua função numa nova realidade social: as cortes medievais. Com isso em mente, não remontamos, aqui, a origem do bobo, que, como já salientamos, anda pari passu com a dos bufões. Buscamos, antes, as origens da profissão de bobo da 


\section{Revista do SELL}

v. $4, n^{\circ} .2$

ISSN: $1983-3873$

corte, quando esta se estabelece na sociedade medieval europeia. Nesse intuito, baseamos nossa apresentação nas descrições do riso no período medieval feitas por Bakhtin (2010a) e Minois (2003).

Em linhas gerais, segundo Bakhtin (2010a), apesar de todas as ações contrárias da Igreja, que reduzia (e regulamentava) os períodos propícios ao riso (por exemplo, às festas religiosas e ao carnaval), o riso ainda podia ser encontrado, na Idade Média, em vários espaços: nos mosteiros, na praça pública, nas residências particulares, no castelo e, mais tarde, no palácio real. Todavia, o surgimento e a existência do bobo, com seu riso ecoante e louco, seu chapéu de guizos, sua seminudez, sua clava - que mais tarde passará a bastão, em analogia ao cetro real -, estão estreitamente condicionados, num primeiro momento, ao sentimento de inversão do mundo desencadeado durante essas festas e ao jogo parodístico (a cópia deformada). À exceção das festas, o bobo (tido como parvo, estúpido e louco) é caçado a pedradas: um ser de quem a comunidade teria o prazer de se livrar, de acordo com Minois (2003, p. 227).

Nesse mesmo tempo, no castelo senhorial, o riso é proporcionado pelas gabs narradas pelos cavaleiros do rei que, com um riso homérico e histórias extravagantes, ridicularizam os adversários derrotados. Entretanto, quando se passa ao palácio real, o riso é orquestrado pelo REX FACETVS. Este último, agora, regulamenta o riso e institui aquele que tem o ofício (ou melhor, a obrigação, que podia se estender de forma vitalícia) e a licença (legitimação) de fazer rir: o bobo da corte.

Sobre esse ofício, Minois (2003, p. 227) nos esclarece que "a instituição não é nova, mas conhece, nessa época, um grande desenvolvimento, a ponto de não somente os grandes senhores mas também as municipalidades e as corporações terem feito questão de adotá-lo, um pouco como mascote." Havia, agora, seleção para bobo, feita com base na estrutura física e no aparente estado cognitivo dos candidatos: débeis mentais, aleijões e anões são colecionados nas cortes, ou mesmo, adquiridos em centros de formação de bobos. Sua aparência física é reforçada pelo uso de um capuz com orelha de asno, que representa a mescla de ignorância e sensualidade. Às vezes, tinha 0 "crânio raspado, com exceção de uma mecha frontal"; às vezes, era "vestido magnificamente, como o próprio rei" (MINOIS, 2003, p. 228).

Além de fazer rir, segundo Minois (2003, p. 230-232), o bobo desempenha outras funções na corte como, por exemplo: i) aconselhar o rei em vários assuntos (política, religião, economia etc.), perturbando, distorcendo as regras do jogo e criando intrigas entre os membros da corte, de preferência em relação aos conselheiros do rei; ii) dizer a 


\section{Revista do SELL}

v. $4, n^{\circ} .2$

ISSN: $1983-3873$

verdade, num contexto no qual o rei é cercado de lisonjas, elogios e mentiras, trazendo, assim, o rei para a realidade; iii) lembrar ao rei que ele é apenas um mortal, partilha da condição humana, para evitar que mergulhe na embriaguez do poder solitário; iv) representar a voz da oposição diante do rei e, sob a proteção da loucura e do riso, ser um verdadeiro anti-rei, soberano invertido, conscientizando o rei dos limites do seu poder despótico. Vendo-se encarregado dessas funções, o bobo mostrava, então, que de bobo não tinha nada: seguro do apoio real, ele usava da sua esperteza para a desonestidade (angariar lucros com intrigas ligadas à vida dos membros e dos funcionários da corte), a ponto de os moralistas o considerarem o próprio diabo, cujo fim deveria ser a fogueira. Diante de semelhante quadro, não é de se espantar que a corte desejasse, por vezes, a morte do bobo e que arquitetasse, em momento propício, o fim dessa profissão real. $\mathrm{E}$ isso não tardou a acontecer.

As mudanças sociais e culturais pelas quais passou a Europa, a partir do Renascimento, iriam tornar os séculos posteriores difíceis para o bobo. Juntam-se a isso o Absolutismo e o desenvolvimento da ciência de base cartesiana que fazem com que as monarquias repensem o papel desse sujeito: "a maioria da [intelligentisia] está relacionada com o fortalecimento da hierarquia, que culminou, no final do século XVII, num desprezo genérico e neoclássico por todos os tipos de humor mais baixos" (BREMMER; ROODENBURG, 2000, p. 23). O rei assume caráter mais que divino, e não se pode mais zombar do lugar-tenente de Deus na Terra. Como consequência, o bobo troca o riso pela bajulação devido ao medo do hospício, que se apresenta sempre como o lugar mais propício para esse louco, resquício de uma época de barbárie e de um riso desmedido. "O bobo do rei, se subsiste, não é mais que uma diversão privada, um palhaço doméstico" (MINOIS, 2003, p. 359). De fato, nesse contexto, tanto o riso quanto a função do bobo se degeneram, perdendo, de acordo com Bakhtin (2010a), seu poder regenerador e libertador. Ele, o bobo, se torna, agora, uma espécie cancioneiro, porta voz de boletins satíricos sobre as questões reais. A bufonaria, a chularia, a linguagem coloquial são expulsas da corte; as formas reduzidas do riso as substituirão. É o momento das piadas de salão, da ironia fina, do chiste, e do surgimento do man of humour.

\subsubsection{HUMORISTA, SIM... MAS NO VERDADEIRO SENTIDO DA PALAVRA}

Da mesma maneira que, no passado, termos como cômico, bufão, bobo, satírico eram tomados - e, por muitas vezes, ainda são - uns pelos outros; atualmente, os usos 


\section{Revista do SELL \\ v. $4, n^{\circ} .2$ \\ ISSN: $1983-3873$}

que se faz do termo humorista levam, em muitos casos, os profissionais do riso a serem confundidos entre si, ou seja, comediantes, cartunistas, chargistas, caricaturistas, entre outros são tidos como humoristas. Ao que tudo indica, essa questão está diretamente ligada à definição de humorista, que carrega, em si, uma carga histórica de problemas semânticos desde sua origem no final do século XVII. Tais problemas, por sua vez, estão ligados ao termo humor e seus equivalentes (ing.) humour e (fr.) humeur.

No decorrer dos séculos século XV e XVI, o termo humor possuía uma grande flutuação de usos na Europa, circunscrevendo dois campos semânticos. O primeiro dizia respeito a questões psicológicas (e patológicas) relacionadas à reinterpretação dos humores (fluidos corpóreos) como humor (estado/disposição de espírito), donde o fato de a definição de humorista se aproximar da de humoralista. O segundo campo semântico correspondia ao entendimento de humor (mais especificamente, humour) como uma questão de estética psicológica, ou seja, uma característica de estilo (aparentada do ing. wit e do fr. esprit) de determinados escritores e poetas que sabiam balancear, em suas obras, riso e melancolia. Segue que o riso assume formas reduzidas, e os sujeitos do riso tendem a se profissionalizar nas fronteiras pouco precisas entre os campos da literatura, do jornalismo e da publicidade. Com base nessa ideia, alguns autores consideram ser esse o momento do "nascimento" do humorista - no sentido moderno e, como veremos mais adiante, pouco definido do termo.

\subsubsection{THE MAN OF HUMOUR E O MOLHO INGLÊS TIPO EXPORTAÇÃO}

A teoria dos humores, primeiramente desenvolvida na Antiguidade por Hipócrates e, mais tarde, reformulada por Galeano, é, de certo modo, retomada e amplamente discutida na ciência médica na Europa Renascentista. Nesse contexto, entretanto, buscase associar essa teoria não somente a uma medicina da matéria (os humores enquanto fluidos corporais: sangue, bílis, fleuma, atrabílis), mas também a uma medicina da alma (do espirito), procurando respostas para os desequilíbrios de temperamento e para as desordens funcionais. Com isso, nos séculos XV e XVI, seguindo a proposta de Escarpit (1972), a palavra de origem latina humor (e seus equivalentes na grande maioria das línguas vernáculas europeias) é tida por um vocábulo de certa forma banal, usado sem maiores preocupações de exatidão de sentido, aberto a várias significações, aparecendo nas discussões e polêmicas (não só médicas, mas também do senso comum) em expressões do tipo: "mau humor"; "bom humor"; "humor virado"; "humor azedo"... 


\section{Revista do SELL}

v. $4, n^{\circ} .2$

ISSN: $1983-3873$

Sabedor dessa flutuação de sentido, a Ben Johnson, comediógrafo contemporâneo de Skakespeare, coube a inserção do termo inglês humour, com sua obra Every man out his humour, na arte dramática e literária inglesa. Segundo Escarpit (1972, p. 13-16), Ben Johnson vê nesse termo a possibilidade de explicar ao público a sua concepção (nova) de comédia. Baseando-se na teoria dos humores, Ben Johnson elabora uma comédia na qual cada personagem é caracterizada (psicologicamente) pela predominância de um tipo de humor: o colérico; o fleumático; o melancólico etc.

É bem verdade que, na Europa continental, também se reflete sobre os humores na estética da arte barroca - em voga naquele momento e que, de acordo com Pirandello (1996, p. 19), ligava, por vezes, o humor a fantasia, capricho, e o humorista, a fantástico. Todavia, como ressalta Escarpit (1972), enquanto que nos outros autores as personagens somente apresentam humores (por exemplo, Hamlet é melancólico), em Ben Johnson, elas se tornam deliberadamente cômicas, pois, adaptando a patologia dos humores às personagens da comédia, Ben Johnson descobre um modo utilização cômica dos humores, criando, assim, um forte elo entre o humour e o ridículo, que não havia na semântica do termo latino humor.

A partir de então, podemos dizer que, na Inglaterra, se desenvolve sobre o humour uma espécie de circunlóquio na História das Ideias, no qual se relaciona o temperamento ("alma"; "espírito") do povo inglês, a sua língua e, até mesmo, as condições climáticas do país ao sense of humour britânico. Com efeito, justifica-se o humor inglês por meio de "uma dialética entre tendências contraditórias onde cada uma serve alternadamente de máscara a outra, a brincadeira (gracejo) vindo humanizar a melancolia ou a morosidade vindo temperar uma vitalidade muito exuberante" ${ }^{15}$ (ESCARPIT, 1972, p. 23 - tradução nossa). Alega-se como fonte disso a excentricidade (natural ou afetada) própria do povo, portador, ao mesmo tempo, de um otimismo triste e de um pessimismo alegre, resultado, por sua vez, do isolamento da ilha britânica, do seu clima chuvoso e frio etc., que seria uma espécie de "molho" especial típico da literatura daquele país.

Diante de tal quadro, é necessário atentar para um ponto em especial que, de certa forma, tornará possível pensar o humour enquanto produto de exportação inglês, a saber: a discussão sobre o caráter (imanente ou estratégico) da excentricidade aferida ao humorista. Com esse objetivo, Escarpit (1972, p. 27 et seq.) nos explica isso a partir da

\footnotetext{
15 No original: "une sorte de dialectique entre des tendances contradictoires dont chacune sert alternativement de masque à l'autre, la plaisanterie venant humaniser la mélancolie ou la morosité venant tempérer une vitalité trop exubérante."
} 


\section{Revista do SELL}

v. $4, n^{\circ} .2$

ISSN: $1983-3873$

aproximação entre o sense of humour e outra importante questão psicológica: o selfconsciousness. Segundo Escarpit, essa última não deve ser entendida como simples consciência de si, mas sim uma consciência que a pessoa (no caso especial, o humorista) possui de que está sendo observado por outrem, o que, por vezes, é confundida com pudor ou timidez, mas que não exclui a malícia, a audácia ou a coragem. Ou seja, é a consciência daquele que se percebe enquanto um personagem, o que possibilita, entre outras coisas, ao humorista desenvolver estratégias - digamos: discursivas - como, por exemplo, a piscadela de olho (a busca da cumplicidade), o gracejo com ar triste (o tom melancólico), a observação aberrante numa frase imperturbavelmente grave, entre outras, de modo a fazer passar não somente a mensagem (a ideia), mas também algo do riso (sua malícia, sua audácia) de forma atenuada, ou, melhor, dissimulada.

Escarpit (1972, p. 36), entretanto, nos alerta que - e aqui está a grande questão ainda no século XVII, começa-se a especular se essas estratégias são próprias do caráter humorista, ou se ele as desenvolve por meio de alguma técnica e/ou estudo. Em outras palavras, se há aqueles sujeitos que sofrem de uma excentricidade imanente, que possuem um modo próprio de sentir e de ver as coisas do mundo (humoristas passivos); ou se há aqueles que possuem consciência do caráter voluntário da composição humorística, mostrando, assim, os efeitos dessa excentricidade calculada no seu discurso (humoristas ativos):

\footnotetext{
Um Homem de Humor (Man of Humour) é um homem capaz de representar com alegria uma personagem fraca e ridícula na vida real, seja assumindo a si mesmo como personagem, seja fazendo isso por meio da representação de outra pessoa, de uma maneira tão natural que se possa, por assim dizer, tocar com o dedo as bizarrices e as fraquezas mais extravagantes da personagem.

Um Humorista (Humorist) é uma pessoa da vida real, obstinadamente presa às bizarrices particulares de sua própria criação, bizarrices que são visíveis no seu temperamento e na sua conduta.

Enfim, um Homem de Humor é um homem capaz de representar e de revelar com alegria as bizarrices e as fraquezas de um humorista ou de outras personagens ${ }^{16}$. (MORRIS, 1744, p. 13 apud ESCARPIT, 1972, p. 36 - tradução nossa)
}

\footnotetext{
${ }^{16}$ Em francês: "Un Homme d'humour (Man of Humour) est un homme capable de représenter avec bonheur un personnage faible et ridicule dans la vie réelle, soit en l'assumant lui-même, soit en le faisant représenter par une autre personne, d'une façon si naturelle qu'on pourra, pour ainsi dire, toucher du doigt les bizarreries et les faibles les plus extravagants du personnage." "Un Humoriste (Humorist) est une personne de la vie réelle, obstinément attachés à des bizarreries particulières de son propre cru, bizarrires qui sont visibles dans son tempérament et dans sa conduite." "Bref, un Homme d'Humour est un homme capable de représenter et de révéler avec bonheur les bizarreries et les faibles d'un humoriste ou d'autres personnages."
} 


\title{
Revista do SELL
}

v. $4, n^{\circ} .2$

ISSN: $1983-3873$

Nessa passagem, vemos as definições man of humor e de humorist do ponto de vista de um pensador do século XVIII. Nela, é importante ressaltar a capacidade digamos: mais técnica - do man of humour em representar várias personagens, inclusive um humorista, sendo que o inverso nem sempre é possível. De outro modo: todo man of humour pode representar um humorist, mas nem todo humorist tem necessariamente a capacidade de representar um man of humour.

Embora concorde com essa linha de raciocínio, Escarpit (1972, p. 37) nos adverte que devemos fazer uma inversão dessas definições, uma vez que o que entendemos, hoje, por humorista (ativo) é o man of humour daquela época, e, em contrapartida, o que entendemos atualmente por man of humour é o humorista (passivo) no pensamento do século XVIII, o que nos leva, ainda nas palavras desse autor, a importantes implicações. Primeiramente, se se considera que essa excentricidade é uma característica calculada (capaz de ser percebida no discurso) do humorista, pode-se dizer que, para além das terras inglesas, essa mesma capacidade estratégica se desenvolve (mesmo que com outros matizes) em outros povos e outras literaturas, não importando os limites históricos e as fronteiras sociais, culturais ou linguísticas. Sendo assim, é possível supor a existência de uma universalização, não menos complexa e repleta de ressalvas, do humorismo, como a que propõe, por exemplo, Pirandello:

\begin{abstract}
Não se pretenderá que os Italianos ou os Franceses tenham o humour inglês, como não se pode pretender que os Ingleses riam à nossa maneira [dos italianos] ou tenha o mesmo espírito dos Franceses. [...] O humorismo próprio e verdadeiro é uma outra coisa, e também é para os Ingleses uma excentricidade de estilo. Basta confundir uma coisa com outra [...] para que se venha a reconhecer uma literatura humorística em um povo e negá-la em um outro. Mas se pode ter uma literatura humorística apenas sob esta condição, isto é, fazendo esta confusão, e então cada povo terá a sua, assumindo todas as obras nas quais este humor típico se exprime nos mais bizarros modos... (PIRANDELLO, 1996, p. 118 - grifos do autor)
\end{abstract}

Em segundo lugar, se se considera essa mesma excentricidade parte imante do man of humour (humorista passivo), pode-se admitir que o humour é uma característica própria da consciência social e cultural inglesa, com o qual sujeito "aparenta ser grave e sério, mas pinta os objetos de tal maneira que provoca a alegria e o riso" (HOME, 1762, p. 161 apud MINOIS, 2003, p. 424). Logo, diremos que esse humor é uma espécie de "molho inglês": uma analogia que acreditamos não ser de todo gratuita, pois sabemos que vários estudiosos do riso e do risível, por vezes, relacionam o riso, o risível e o fazer rir com certa percepção de sabores que extrapola a simples questão do paladar. 


\section{Revista do SELL}

v. $4, n^{\circ} .2$

ISSN: $1983-3873$

Nessa linha, podemos citar os antigos retores e retóricos, entre eles Aristóteles, Cícero e Quintiliano, que consideravam o uso riso nos discursos, uma capacidade inata de alguns sujeitos e que dificilmente se poderia ensinar, semelhante à técnica de temperar a comida, ou seja, esses pensadores acreditavam que o riso era como SAL ou SALSVM (lat. "sal"; "molho picante") que dá gosto e realça, mas que, ao mesmo tempo, deve ser adicionado com parcimônia e sabedoria para não estragar a comida (ou o discurso). De certo modo, assim também pensamos o caso do humour inglês: um tipo de molho especial que engendra, com medidas específicas, em si mesmo, o riso, a melancolia, a seriedade e o pessimismo, e que, de modo semelhante a outros molhos espalhados pelo mundo (por exemplo, a salsa cubana, o shoyu, o barbecue, entre outros) marca de modo muito caraterístico a cultura em que eles foram criados. Esses molhos podem ser exportados ou, até mesmo, copiados em outros lugares; porém, sempre têm a nação de origem como referência sobre seu sabor.

A respeito disso, Pirandello (1996, p. 22-23) ressalta o entendimento que a opinião pública (do final do século XIX e início do XX) tinha sobre o "ser" humorista: "para muita gente escritor humorístico é o escrito que faz rir [...] como por hábito, se costuma chamar romântico tudo o que há de mais arcaico e sentimental, de mais falso e barroco". Uma confusão, como alega Pirandello, que tende a piorar a partir do momento em que o jornalismo adota o humorismo e, "esforçando-se para fazer rir mais ou menos de modo vulgar e a todo custo", constrói o que Pirandello chama de um "falso sentido" do que seja um humorista. Daí a reação dos humoristas que passam a exigir ser chamados por "humoristas, sim... mas no verdadeiro sentido da palavra". Sentido que aguardamos atenciosamente Pirandello nos esclarecer; todavia, como elucida Eco (1989), o que conseguimos, ao termino da leitura de Pirandello, é aumentar nossas dúvidas, confundido humorismo, humorista, humor, humour, cômico, ironista, ironia, ridículo, filosofia, arte, vida, poética etc.

Não é sem razão que o próprio Pirandello considere que é exatamente essa "confusão" - que Eco (1989) entende, no todo do ensaio, como uma forma de definição deveras imprecisa e desastrada - a possibilidade de enxergar e de definir o humorismo, deixando em aberto o problema. Para Eco, isso reflete bem o pensamento de Pirandello que "gostava de expor só problemas para os quais não tinha solução" (ECO, 1989, p. 250). Apesar disso, devemos ressaltar que Pirandello (1996, p. 155) fornece uma distinção entre humoristas e comediantes, cômicos, ironistas etc. Essa se fundamenta na diferença entre o sentimento do contrário (próprio do humorista, cuja função é colocar 


\section{Revista do SELL}

v. $4, n^{\circ} .2$

ISSN: $1983-3873$

sobre as formas cômicas um certo amargor, derivado do fazer-refletir o cômico) e a percepção do contrário (própria dos demais sujeitos do riso, que dão livre curso ao riso e as suas formas).

\section{CONSIDERAÇÕES FINAIS}

Pelo exposto até aqui, vimos que os traços que definem o retrato do sujeito do riso são muito tênues, o que faz tentar confirmar tais definições, a partir do discurso, uma empreitada das mais complexas. No entanto, esses mesmos traços e características nos proporcionam direcionar nosso olhar para o que está na base do entendimento do que sejam esses sujeitos e, em especial, do que seja um humorista - no seu sentido atual e aparentemente indefinível. Ou seja, vislumbrar a querela existente entre profissionais do riso nos leva, de um modo ou de outro, à questão paradoxal expurgo do riso dos gêneros típicos do humor.

\section{REFERÊNCIAS}

ARISTÓTELES. Retórica. Cidad Universitária, México, D. F.: Universidad Autónoma do México, 2002.

ARISTÓTELES. Poética. Lisboa: Fundação Calouste Gulbenkian, 2004.

BAKHTIN, M. M. A cultura popular na Idade Média e no Renascimento: o contexto de François Rabelais. 7 ed. São Paulo: Hucitec, 2010a.

BAKHTIN, M. M. Questões de literatura e de estética: a teoria do romance. 6 ed. São Paulo: Hucitec, 2010b.

BREMMER, J. Piadas, comediógrafos e livros de piadas na cultura grega antiga. In: BREMMER, J.; ROODENBURG, H. (orgs) Uma história cultural do humor. Rio de Janeiro: Record, 2000, p. 27-50.

BREMMER, J.; ROODENBURG, H. Humor e história. In: BREMMER, J.; ROODENBURG, H. (orgs) Uma história cultural do humor. Rio de Janeiro: Record, 2000, p. 13-25.

CHARAUDEAU, P. Discurso Político. São Paulo: Contexto, 2006.

CHARAUDEAU, P. Des catégories pour l'humour. Précisions, rectifications, complements. In: VIVERO, M. D. (dir.) Humour et crises sociales. Regards croisés France-Espagne. Paris: L'Harmattan, 2011, p. 9-43.

ECO, U. Pirandello ridens. In: Sobre espelhos e outros ensaios. Rio de Janeiro: Nova Fronteira, 1989.

ESCARPIT, R. L'humor. 5 ed. Paris: Presse Universitaires de France, 1972.

GRAF, F. Cícero, Plauto e o riso romano. In: BREMMER, J.; ROODENBURG, H. (orgs) Uma história cultural do humor. Rio de Janeiro: Record, 2000, p. 51-64. 


\section{Revista do SELL}

v. $4, n^{\circ} .2$

ISSN: $1983-3873$

HOME, H. Elements of criticism. Londres, 1762.

HOUAISS, A. Dicionário eletrônico Houaiss da língua portuguesa. São Paulo: Objetiva, 2009.

JAEGER, W. A comédia de Aristófanes. In: Paidéia: a formação do homem grego. São Paulo: Martins Fontes, 1995, p. 414-439.

LESKY, A. Os começos do drama. In: História da literatura grega. Lisboa: Fundação Calouste Gulbenkian, 1995, p. 253-271.

MAINGUENEAU, D. Análise de textos de comunicação. 3 ed. São Paulo: Cortez, 2004.

MALHADAS, D.; DEZOTTI, M.; NEVES, M. H. M. Dicionário grego-português. Cotia: Ateliê, 2006.

MINOIS, G. História do Riso e do Escárnio. São Paulo: Editora UNIESP, 2003.

MORRIS, C. An essay towards fixing the true standards of wit, humour, raillery, satire and ridicule. Londres, 1744.

PINTO, Z. A. Ninguém entende de humor. Revista de Cultura Vozes. Rio de Janeiro: Vozes, n. 3, vol. LXIV, 1970, p. 21-37.

PIRANDELLO, L. O humorismo. São Paulo: Experimento, 1996.

PLATÃO. O banquete. In: Diálogos. 2 ed. São Paulo: Abril Cultural, 1985, p. 1-54. 